\title{
Bias in Science: Natural and Social
}

\author{
Joshua May
}

\author{
Forthcoming in Synthese
}

\begin{abstract}
Moral, social, political, and other "nonepistemic" values can lead to bias in science, from prioritizing certain topics over others to the rationalization of questionable research practices. Such values might seem particularly common or powerful in the social sciences, given their subject matter. However, I argue first that the well-documented phenomenon of motivated reasoning provides a useful framework for understanding when values guide scientific inquiry (in pernicious or productive ways). Second, this analysis reveals a parity thesis: values influence the social and natural sciences about equally, particularly because both are so prominently affected by desires for social credit and status, including recognition and career advancement. Ultimately, bias in natural and social science is both natural and socialthat is, a part of human nature and considerably motivated by a concern for social status (and its maintenance). Whether the pervasive influence of values is inimical to the sciences is a separate question.
\end{abstract}

Word count: 9,314 excluding references and abstract (11,198 total)

Keywords: values in science; wishful thinking; conflicts of interest; replication crisis; research integrity; motivated reasoning; rationalization

\section{Introduction}

Science has long been influenced by financial conflicts of interest, politics, and other biases. The replication crisis and high-profile cases of misconduct, however, have renewed concerns about the generation of biased data and conclusions, owing perhaps to the outsized influence of apparently "nonepistemic values," such as political ideology and personal gain. Due to a number of factors-e.g. low sample sizes, small effect sizes, and ideological influences - one prominent scientist famously estimated that most published scientific findings are false (Ioannidis 2005). A key concern is that a researcher's preferences or values can contribute to the rationalization of experimental designs or interpretations of data that will bring the researcher status, support their favored ideology, or promote what they perceive to be social justice (see e.g. Wilholt 2009).

Social science has received a disproportionate amount of criticism and skepticism. With headlines like "How Academia's Liberal Bias is Killing Social Science" in The Week (Gobry 2014) and "Social Sciences Suffer from Severe Publication Bias" in Nature (Peplow 2014), there certainly appears to be a "crisis of confidence" about findings in these fields (Pashler \& Wagenmakers 2012: 528). Similar sentiments can be found in the popular media, such as The Washington Post, which has dispassionately stated: "The social end of the science spectrum is notorious for publishing questionable research, even in the most well-respected journals" (Gebelhoff 2017). In Scientific American, the science writer 
Michael Shermer maintains that ideological bias is "much worse in the social sciences" (2016).

One might think the influence of values is more prevalent in social science because such researchers will be most motivated by moral and political agendas. As a team of personality and social psychologists themselves put it, theirs "is the subfield of psychology that most directly examines ideologically controversial topics, and is thus most in need of political diversity" (Duarte et al. 2015: 2). Similarly, Steven Pinker recently writes: "Moralization is the original sin of the behavioral sciences. ...it's irresistible to read our morals into reality and describe the world as if it strove to implement our values" (in his forward to Fiske \& Rai 2014). Not only is the subject matter of social science replete with values, the phenomena studied are highly complex and thus "the connection between theories, hypotheses and empirical findings could be more flexible, negotiable and open to interpretation" (Fanelli 2010: 6-7; see also Fanelli et al. 2017).

I argue, however, for a parity thesis: despite some differences, the influence of values is not significantly more prevalent in the social compared to the natural sciences. The argument turns chiefly on two mutually reinforcing claims. The susceptibility claim is that a variety of values influence all sciences, including ideological motivations that might seem particular to the social sciences. The minority claim is that ideological motivations are less powerful and pervasive than other motives, such as profit and social credit, which are present throughout science. The analysis develops motivated reasoning as a unifying framework for how values influence science - whether in pernicious, benign, or productive ways. Although the archetypes of motivated reasoning, such as wishful thinking and confirmation bias, are often regarded as inimical to knowledge production in science (e.g. Anderson 2004; Brown 2013), the parity thesis does not take a stance on whether and when such influences are epistemically problematic, pushing science away from its primary aim of acquiring knowledge (cf. Solomon 2001; Bright 2017). I argue only that bias in the natural and social sciences is both natural and social - that is, a part of human nature and considerably motivated by a concern for social status - which reveals just how inevitable and inherent values are in all of science.

\section{Values and Bias}

The term "bias" is often used pejoratively to refer to unfairly or unwarrantedly favoring an idea or individual, as when a coin is biased toward heads or a jury member's bias against women produces a tendency toward distrusting their testimony. In the context of scientific investigation, a preference for a certain idea (e.g. a hypothesis, interpretation, or approach) can deviate from truth or be unwarranted by the evidence. Importantly, however, the term "bias" can be used even more broadly to include nobler tendencies toward accepting a particular conclusion, such as a bias toward the truth. Let us broadly say that in human psychology a bias is a tendency to favor a certain conclusion. Although in paradigmatic cases the conclusion is favored in an unwarranted way, we'll see that it isn't inherently objectionable to have one's reasoning guided by one's goals and values.

In science, an investigator's values can readily serve as sources of bias. Since one's values generally give rise to corresponding motivations, they can influence various decisions made during scientific investigation. For example, a researcher's values and goals can sway choices about how to test hypotheses, describe the results, and assess the 
evidence (see e.g. Elliott 2017), and corresponding labels are often given, such as "design bias" and "analysis bias" (Stegenga 2018: ch. 10; Fanelli et al. 2017). Even the decision to publish or report a particular finding (or null result) can be influenced by a researcher's desire to construct a manuscript narrative that is more likely to survive peer review-a form of publication bias (Franco et al. 2014). Such decisions are arrived at through reasoning - sometimes deliberate, sometimes unconscious - which makes a framework of "motivated reasoning" apt. Before analyzing bias in terms of motivated reasoning, though, it will be useful to consider some examples of bias in science.

Discussions of values in science often focus on how industry-funded research spawns financial and political conflicts of interest. In light of the recent replication crisis, however, some discussions have focused on various "questionable research practices" that make one's studies more likely to produce a statistically significant result (see e.g. Nosek et al. 2012; Peterson 2019). Many scientists have powerful personal, professional, and ideological motivations to engage in such practices in order to rack up more publications, especially in more prestigious journals, which prefer exciting findings that substantially advance the cutting edge of research. One recent study collected anonymous responses from over 2,000 psychological scientists about their own engagement in ten questionable research practices (John et al. 2012), and the vast majority of respondents (91\%) admitted to engaging in at least one of them. Of the practices, three stand out as most common, given that about half of respondents (45-65\%) reported engaging in them:

- failing to report all of a study's dependent measures

- selectively reporting studies that "worked" (excluding e.g. null results)

- deciding whether to collect additional data after checking to see whether the results were significant (a form of "p-hacking")

Although the survey attempted to incentivize honesty, some respondents probably remained reluctant to even reveal such misdeeds anonymously.

Another questionable practice on the rise is the reporting of and reliance on "marginally significant" results. A p-value of less than 0.05 is the conventional threshold for statistical significance, yet some researchers report slightly higher p-values as significant or "marginally significant" to ultimately support a hypothesis. Over the past few decades, this questionable practice has increased substantially in psychology (Pritschet et al. 2016). Of course, the choice to rely on marginal significance can be motivated by the desire to publish or to advance a desired conclusion. One potential example of both motivations is the widely cited - and apparently only-empirical attempt to demonstrate that blind auditions in orchestras increase the number of women who win auditions by reducing discrimination or implicit bias (Goldin \& Rouse 2000). However, the media and the authors themselves tout the desired conclusion based largely on marginally significant effects with large standard errors (for discussion, see Pallesen 2019).

Another practice influenced by personal goals is the failure to disclose aspects of one's methods or data that could impact conclusions. An example can be found in one of the most famous studies in psychology, the so-called "Stanford Prison Experiment" led by Philip Zimbardo in 1971. As the story goes, Zimbardo randomly assigned healthy male students at Stanford to play the role of either guards or prisoners over the course of two weeks in a basement on campus. Zimbardo shut the study down after only a week because the situation had apparently devolved into guards mistreating prisoners so badly that some begged to be released. In a recent exposé (Blum 2018), however, it appears Zimbardo 
misrepresented the study's design and observations. According to new interviews and old uncovered transcripts of discussions with participants and others present, it was revealed that Zimbardo essentially encouraged the mistreatment, that the prisoners were not quite free to leave for any reason, and that the pleas to be released were likely faked just so the students could get back to their lives (in one case to go study for an important exam).

Such questionable research practices also occur in the natural sciences. One recent study asked over 800 scientists working in ecology and evolutionary biology about how often they and their colleagues engage in questionable practices (Fraser et al. 2018). The researchers also directly compared their data to surveys of psychologists and found markedly similar results, leading to the conclusion that questionable research practices are "broadly as common in ecology and evolution research as they are in psychology" (p. 9). For example, about two thirds (64\%) of respondents said they had cherry picked which results they reported in articles by omitting null findings that were not statistically significant. And over half (51\%) admitted to claiming that unexpected findings were predicted in advance. Another study mined articles in the PubMed database to estimate the likelihood of p-hacking, defined as acts where "researchers collect or select data or statistical analyses until nonsignificant results become significant" (Head et al. 2015: 1). Studies in the database included many disciplines in the natural sciences-including biology, chemistry, medicine, and geoscience - yet the authors conclude that "p-hacking is widespread in the scientific literature" (11).

Money also exerts a particularly powerful influence in many areas of the natural sciences, given that findings often have direct commercial applications, from the development of prescription drugs to nanomaterials. Companies often have a vested interest in finding certain effects, e.g. that a new drug reduces nausea in cancer patients. Companies also have an interest in finding null results, e.g. that there is no link between a certain plastic material and neurological disorders. It is common that industry-funded research tends to produce markedly different results from government-funded work on the same topic, due to the biased adoption of certain experimental protocols, interpretations of data, and dissemination of results (Wilholt 2009). Biased research funded by the tobacco industry in the mid-twentieth century infamously influenced the study of smoking's adverse health effects (Oreskes \& Conway 2010). While some findings in social science generate commercial applications (e.g. self-help books), the markets for such products are often much smaller.

Of course, publicly funded research can exhibit bias too, such as the tendency to generate effects and avoid null results. One striking example involves the analysis of randomized controlled trials of cardiovascular interventions, funded primarily by the National Institutes of Health. Kaplan and Irvin (2015) compared the rate of null results reported before and after the year 2000, when the detailed plans of such studies had to be pre-registered-i.e., publicly documented before acquiring data and reporting results. Remarkably, while $57 \%$ of the pre- 2000 trials reported an effect of the study's intervention, only $8 \%$ of those published afterward did. As the authors explain, "Prior to 2000, investigators had a greater opportunity to measure a range of variables and to select the most successful outcomes when reporting their results" (8). 


\section{Reasoning Motivated by Values}

Various social and psychological factors can explain how values influence science. But we will focus on how reasoning generally, including scientific reasoning, can be nudged toward certain conclusions by values that are embodied in one's motivations. This framework applies to a wide range of cases, from the influence of industry-funded research to personal desires to achieve recognition.

\subsection{Motivated Reasoning}

Reasoning or inference is the process of forming or changing beliefs on the basis of other beliefs or credences (Boghossian 2012). For example, I conclude (form the belief) that smoking causes cancer on the basis of my acceptance of (belief in) the scientific consensus, and I conclude that I shouldn't smoke on the same grounds. Such reasoning processes can, of course, be influenced by one's values and goals. Confirmation bias, for example, is the notorious and ubiquitous tendency to search for and interpret new evidence as supporting conclusions that one already accepts (Kahneman 2011: 81). A teenager's desire to fit in with his peers who smoke can lead him to doubt the severity of the health risks or inflate the benefits so that they seem to outweigh the costs. Sometimes we form beliefs noninferentially, as when we take our perceptual experiences at face value and simply believe what we see. But it's controversial to what degree observations themselves can remain independent of one's goals and values (that is, whether there is "cognitive penetration" of perception; see Firestone \& Scholl 2016; Peterson 2019). However, even if we don't always just see what we want to see, we can certainly justify what we want to justify. And much of the scientific enterprise involves reasoning or inference that is open to being so motivated.

Indeed, cognitive biases often work through reasons. Instead of merely opting for the conclusion one prefers, human beings curiously come up with reasons, even if dubious ones, in order to justify their decisions to others and, importantly, to themselves. Coming up with reasons for a specific conclusion is just what we colloquially call "rationalization," which is often used in a pejorative sense, but it has a non-pejorative use as well (see Davidson 1963). Sometimes we make a choice or form a belief automatically or intuitively and only afterward - post hoc - come up with a justification for why, and one that doesn't necessarily correspond with the reasons that actually drove one to the conclusion in the first place. One might be certain that incest is immoral, but the rationale one gives that it's harmful won't necessarily apply to a one-off instance of protected intercourse among adult cousins (Haidt 2001). Sometimes this is called "confabulation" in psychiatry and neurology, but it is common in ordinary life.

Reasoning and rationalization can also occur before a decision - ante hoc - in order to justify it in the first place (May 2018). The most familiar ante hoc rationalization is a form of motivated reasoning, which has been studied extensively (Kunda 1990; Ditto et al. 2009). You want a beer with lunch, and because you first justify it as deserved, given how busy the morning has been, you imbibe. Or you want to believe that your favorite team will win, so you first rationalize that the star player's injury is but a flesh wound.

Construed broadly, however, motivated reasoning is just reasoning shaped by one's goals, desires, or preferences. This needn't be irrational at least because one's inferences 
can be driven by the desire for truth or accuracy (Kunda 1990). In science, such a "veritistic" motive could even incentivize questionable research practices in order to promote a finding that one is already convinced is true (Bright 2017). Like biases, motivated reasoning is thus neither virtuous nor vicious in itself, even though the term is often used pejoratively and to only refer to reasoning that is guided by motives other than truth. Moreover, whether motivated by truth or other values, reasoning can occur before or after the relevant conclusion is drawn or decision made (ante hoc or post hoc). For example, Beck may go into therapy already thinking he's a loser, but his present attempts to scrutinize that belief are motivated by a desire for self-knowledge, not wishful thinking. Similarly, although a scientist may embark on a research project with the intuitive belief in her pet theory, her attempts now to seek evidence for or against it can be motivated purely by a desire to seek the truth.

Importantly, to accept the existence, even prevalence, of human biases is not to accept the postmodernist doctrine that truth is always relative and objectivity impossible. The point, rather, is a commonsense one: while truth and objectivity are possible, humans are fallible and conflicts of interest can get in the way, due to various forms of rationalization. Such biases can certainly conflict with the scientific enterprise, given its fundamental commitment to truth and justification. But this epistemic commitment alone can't neutralize motivated reasoning or rationalization, given that they work by generating justifications, even if spurious ones. Moreover, given the level of self-deception that frequently co-occurs with rationalization, the influence of one's goals and values often go unnoticed.

Many philosophers of science have argued that values in science are inevitable and aren't inherently problematic (e.g. Longino 1990; Kitcher 2001). For example, as Elizabeth Anderson (2004) documents, prior to the 1990s many researchers studying divorce consistently looked only for negative effects on children, which presumed "traditional family values." To even look for positive or neutral effects of divorce on children, it took researchers with a different set of values that arose from a more feminist approach to the issue. So, as Anderson notes, it's not a problem for values to influence science, especially when they open new avenues of neglected inquiry. The problem is when values become self-fulfilling prophecies or "operate to drive inquiry to a predetermined conclusion" (Anderson 2004: 11). This concern in philosophy of science has been called the problem of wishful thinking or "claiming that something is the case because one wishes it were the case" (Brown 2019: 227).

Wishful thinking is often a form of motivated reasoning, but they are distinct for at least two reasons. First, "motivated reasoning" needn't be a pejorative term, as when one's reasoning is influenced by a desire to be accurate, whether because accuracy is incentivized or intrinsically valued. Second, "wishful thinking" often connotes the forming of a belief that would promote one's narrow self-interest, but motivated reasoning is not restricted to a certain class of desires. Partisan citizens who interpret all of the president's actions in a positive light, even those detrimental to their own economic well-being, exhibit motivated reasoning even if not wishful thinking. Similarly, although the hasty conviction of an impatient jury can amount to wishful thinking, the protracted deliberations of a conscientious judge do not, even if her verdict is driven by a powerful desire to avoid injustice. In practice, many cases of motivated reasoning are appropriately described as wishful thinking. Nevertheless, the former provides a broader and unified understanding 
of when various values, in the form of motivations, guide scientific reasoning, whether in problematic or acceptable ways (see Figure 1).

\section{Figure 1: A Taxonomy of Motivated Reasoning}

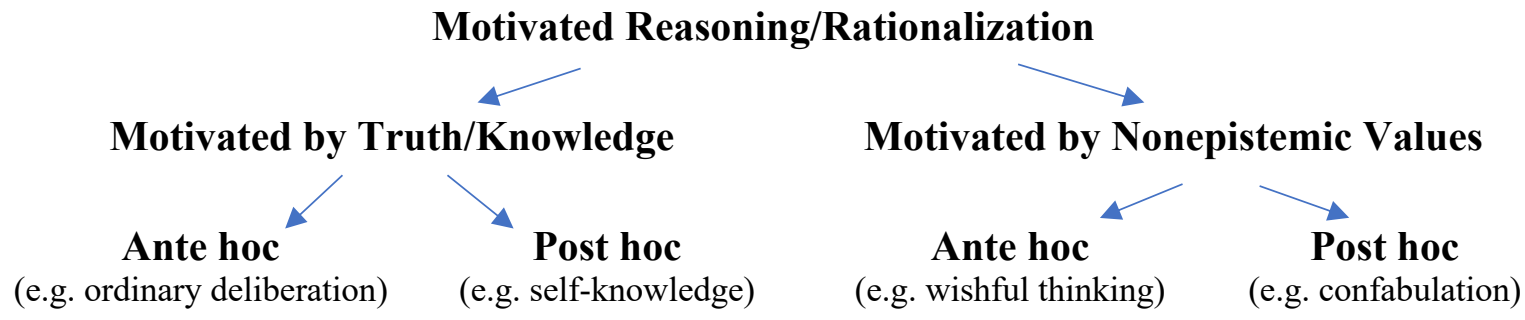

\subsection{Biased Reasoning}

Motivated reasoning is such a core part of the human condition that it naturally occurs in both everyday life (Kunda 1990) and the scientific enterprise (Koehler 1993; Nosek et al. 2012; Stegenga 2018: 108). Whether post hoc or ante hoc, reasoning motivated by values can influence scientific investigations. For example, if a researcher wants badly to publish in a prestigious journal, ante hoc rationalization can help to justify engaging in questionable research practices. Similarly, researchers motivated to detect a positive effect of a new drug may inadvertently use experimental designs more likely to produce the desired outcome and later (post hoc) rationalize their protocol as unbiased to peer reviewers. Such rationalizations can allow values to meet the "criterion of illegitimate guidance" in science, wherein they serve as self-fulfilling prophecies, driving an inquiry toward a predetermined conclusion (Anderson 2004: 11).

The rationalizations in motivated reasoning are sometimes conscious. And this may well represent a key function of conscious deliberation in human beings: to convince others or ourselves of our intuitive verdicts rather than to uncover the truth (Mercier and Sperber 2017). Often this amounts to post hoc rather than ante hoc rationalization, however. Importantly, motivated reasoning can be unconscious and nonetheless powerfully influence the intuitive verdicts themselves. When rationalizations are ante hoc and unconscious, they are particularly apt materials for motivated reasoning that produces the kinds of wishful thinking and self-fulfilling prophecies that represent the apparently problematic form of value-laden scientific inquiry.

A large body of research suggests that reasoning motivated by values is ubiquitous. A meta-analysis of "moral licensing," for example, suggests that people will implicitly justify morally questionable, but personally advantageous, behavior to themselves when they have recently engaged in virtuous acts or affirm their virtuous traits (Blanken et al. 2015). In one study, participants were more likely to cheat if they had recently supported environmentally friendly products (Mazar \& Zhong 2010). This is just one form of motivated moral reasoning, wherein people will unconsciously rely on whatever moral principles help to justify a desired verdict (Ditto et al. 2009). A similar phenomenon is "motivated forgetting," in which we rationalize morally dubious acts or a better self-image 
by failing to recall relevant moral norms or past infractions (Stanley \& De Brigard 2019). The literature suggests that in many circumstances people aren't willing to rationalize fully breaking the rules, but they are happy to "bend" them. One series of studies examined under what conditions people will be dishonest when motivated to earn extra cash in an experiment (e.g. Mazar et al. 2008). Participants were told they would receive money for each math problem solved within a limited amount of time. When payment was based merely on self-reported success, most participants dishonestly reported solving more problems than they did, but just a few more. Most people can rationalize to themselves cheating a little but not a lot (Ariely 2012), due to their conflicting commitments to moral truth and self-interest (May 2018: ch. 7).

Clearly motivated reasoning is not restricted to certain domains and is particularly suited to rationalizing choices that are personally beneficial but otherwise questionable. Some evidence speaks specifically to the social implications of research in the natural sciences, which sparks motivated reasoning. In a large sample of Americans, climate change was perceived to be slightly less threatening among more mathematically and scientifically skilled respondents (Kahan et al. 2012). While the more scientifically savvy liberals in the sample perceived climate change as more threatening to humanity, the more savvy conservative respondents perceived less risk. Apparently, a greater familiarity with science only made participants better able to rationalize their preferred stance on this now politicized issue. A recent meta-analysis suggests that this tendency to evaluate information more positively simply because it favors one's own political views ("partisan bias"), is equally present among both liberals and conservatives (Ditto et al. 2019).

The above studies focus on moral or social motivations, but they paint a picture of motivated reasoning that is particularly relevant to how values influence science generally. Research practices regarded as merely "questionable" are especially subject to motivated reasoning, for there is enough of a fudge factor-enough wiggle room - to justify rulebending to oneself or one's research group.

\subsection{Is Motivated Reasoning Problematic?}

Although many philosophers of science reject the idea that science can or should be entirely value-free, many would regard motivated reasoning as generally problematic, at least given the kind of wishful thinking it often engenders (cf. Elliott 2017; Brown 2013). Nevertheless, some philosophers have argued that motivated reasoning isn't always epistemically problematic. Even post hoc rationalization and confabulation can serve a valuable purpose in trying to make sense of one's automatic and intuitive attitudes (Gazzaniga 1983; Bortolotti 2010; Summers 2017; Cushman 2020). Therapy, for example, might inaccurately identify the source of one's marital problems as narcissism, but the diagnosis might not be far off and promote greater self-understanding in other facets of one's life.

Even if motivated reasoning were always epistemically vicious for the individual, it might often lead to knowledge in science at the aggregate level. The scientific enterprise does have mechanisms for self-correction, including peer review and replication efforts. Although such mechanisms don't always function properly (Estes 2012; Nosek et al. 2012; Stroebe et al. 2012), studies of collective deliberation have shown that individual irrationalities can produce knowledge when conflicting perspectives are put into dialog (Mercier \& Sperber 2017). In this way, recent game-theoretic models suggest that the 
motives of individual scientists, even if self-centered, can produce a greater good through a competitive marketplace of data and ideas (e.g. Zollman 2018; Bright 2017). Much like the invisible hand of the market, individual biases needn't impugn science as a whole (see Solomon 2001, although she rejects the analogy).

Fortunately, we needn't adjudicate here whether and when values, biases, or motivated reasoning are epistemically problematic for science. Rather, our aim is only to assess whether values influence the social sciences significantly more than the natural sciences. It could be that, although both natural and social scientists individually engage in motivated reasoning, the ultimate result is unbiased knowledge. As our present concern is only with the parity issue, we turn to the question of which motivations are likely to influence research in various scientific fields.

\section{The Parity of Natural and Social Science}

\subsection{Motives in Science}

With motivated reasoning as our framework for understanding the influence of values on science, we should consider what motivates scientists. We have already encountered several common motives that can influence an investigator's reasoning, including financial gain, career advancement, ideology, and even truth. However, at any given time multiple motivations can arise that serve quite different end goals.

It is thus imperative to distinguish two kinds of goals, motivations, or desires. Instrumental (or extrinsic) desires are those one has as a means to achieving another goal, such as the desire to take a pill in order to relieve a headache. Ultimate (or intrinsic) desires, on the other hand, are those one has for their own sake, such as the desire to relieve a headache. It is tempting to treat all desires as instrumental except for the desire to gain pleasure or to avoid pain (as the theory of psychological egoism would have us believe). But there is ample empirical evidence that humans ultimately desire more than their own self-interest, including helping others and doing what's right (Fiske \& Rai 2014; Batson 2016; May 2018). Desires for power, fame, prestige, and knowledge are also plausibly valued intrinsically. So it is not a stretch to believe that scientific reasoning is often guided by the desire to produce knowledge for its own sake, which is commonly identified as the ideal. However, scientists can also be motivated to produce novel and interesting results, largely as a means to other ultimate goals, such as career advancement, which bring recognition and social status, even if not financial gain. When such credit is the ultimate goal, it can lead to questionable or otherwise poor research practices, which can frustrate the ultimate aim of acquiring knowledge (Nosek et al. 2012; Tullett 2015). Poor practices can also be rationalized as a means to achieve the ultimate goal of promoting or upholding one's favored ideology. Since one regards the ideology as correct, truth (or acceptance of it) is typically the ultimate goal. However, landing by luck on the truth via the path of wishful thinking does not amount to knowledge; sound evidence is required. Thus, rather than a truth or veritistic motive (contrast e.g. Bright 2017), I prefer to speak of a "knowledge motive," which sharply distinguishes it from the ideology motive.

Scientists no doubt have many ultimate goals, whether held consciously or unconsciously. But four distinct categories stand out: knowledge, ideology, credit, and 
profit (see Table 1). Two of these - profit and credit—are ultimately self-interested, but desires to produce knowledge or the acceptance of an ideology are not egoistic, provided we appropriately understand these as ultimate goals desired for their own sakes. Whether self-serving or not, our framework of motivated reasoning suggests that any of these four ultimate goals can sway scientific investigation toward furthering them.

\section{Table 1: Some Sources of Motivated Reasoning in Science}

\begin{tabular}{ccc}
\hline Ultimate goal & Examples & Means to the End \\
\hline $\begin{array}{c}\text { Knowledge } \\
\text { (production or } \\
\text { acquisition of it) }\end{array}$ & $\begin{array}{c}\text { accurate theories, genuine } \\
\text { experimental effects, explanatory } \\
\text { unification }\end{array}$ & $\begin{array}{c}\text { produce quality data, address } \\
\text { underexplored questions ignored } \\
\text { by rival values, etc. }\end{array}$ \\
\hline $\begin{array}{c}\text { Ideology } \\
\text { promoting the } \\
\text { acceptance of it) }\end{array}$ & $\begin{array}{c}\text { research supports egalitarianism, } \\
\text { theism, denigration of conservatism }\end{array}$ & $\begin{array}{c}\text { produce quality data, fabricate or } \\
\text { misrepresent data, etc. }\end{array}$ \\
$\begin{array}{c}\text { Credit } \\
\text { (acquiring it) }\end{array}$ & $\begin{array}{c}\text { maintenance, career advancement, } \\
\text { academic promotion and honors }\end{array}$ & $\begin{array}{c}\text { produce quality data, fabricate or } \\
\text { misrepresent data, produce novel } \\
\text { findings, explore popular topics, } \\
\text { follow disciplinary norms, etc. }\end{array}$ \\
\hline $\begin{array}{c}\text { Profit } \\
\text { (acquiring it) }\end{array}$ & $\begin{array}{c}\text { produce quality data, fabricate or } \\
\text { misrepresent data, promote } \\
\text { surprising counter-intuitive } \\
\text { findings, etc. }\end{array}$ \\
\hline
\end{tabular}

Of course, science is conducted not only by individuals but by communities. Sometimes it is appropriate to ascribe motives to such groups of researchers, as when a particular laboratory is motivated to achieve collective credit or to promote their favored theory. However, the values within a community do not always reflect the motivations of each individual within it, particularly when it comes to dominant assumptions, ideologies, and stereotypes. Sometimes a community's dominant framework will show up in the motivations of the individuals within it - e.g. motivations to uphold (or at least not flout) stereotypes about testosterone as a masculine hormone (Fine 2010) or about divorce as inherently damaging to a family (Anderson 2004). But the individual and community can diverge. For example, if environmentalism is the most widely accepted ideology within a research community, some individual scientists might produce work that supports (or avoids conflicting with) conservationist policies, not for the ultimate goal of promoting the ideology or policies but as a necessary means to achieving profit or credit within the community's accepted framework. Thus, we can ultimately understand the effects of community-level assumptions in terms of the motivations of individual scientists. But, again, to understand the intrinsic values that influence scientific practice, it is essential to distinguish between the ultimate and instrumental goals of individuals. The question now is which ultimate motivations are most prevalent among scientists.

\subsection{What Motivates Most Scientists?}

It is often difficult to know for sure what ultimately motivates people, let alone most scientists. A natural place to start is to ask them. Since some of the ultimate goals are self- 
serving (profit and credit), some scientists won't be fully truthful when self-reporting their motivations. Nevertheless, interviews, anonymous surveys, and case studies provide some relevant evidence.

In 2009, collaborating with the American Association for the Advancement of Science, the Pew Research Center surveyed over 2,500 scientists about political issues and the nature of the scientific enterprise (Pew 2009). Respondents were primarily in the natural sciences (namely, biological/medical, chemistry, geosciences, physics/astronomy), with only $19 \%$ in the "other" category. Most worked in academia (63\%) with the rest in government, industry, non-profits, or other sectors. Most of the scientists reported opting for their careers in order to "solve intellectually challenging problems," "work for the public good," or "make an important discovery." Remarkably, though, a third admitted that a "financially rewarding career" was very or somewhat important, and the number jumps to about half $(51 \%)$ for the scientists working in industry. Given the stigma attached to doing science for the money, these self-reported attitudes are likely an under-estimation of the reality, particularly among early career researchers who are often paid little for the hours they work and the education level they have attained. These data suggest what is fairly commonsense. Scientists are highly motivated to solve challenging problems and produce knowledge that makes a difference in the world. But they also want to gain from it, partly in the form of financial gain.

Other personal gains include social credit, such as recognition or career advancement. Indeed, competition is fierce across all of the sciences. In a focus group setting, over 50 researchers from the biomedical, clinical, biological, and behavioral sciences reported no positive effects of competition among practitioners in their fields (Anderson et al. 2007). Instead, even though the scientists were not explicitly asked questions about competition, their responses regularly turned to competition and how it often leads to secrecy, sabotage, soured relationships, scientific misconduct, and interference with peer review. Multiple participants mentioned the "practice of taking photographs of poster presentations in order then to publish the results first" (451). Some participants reported that since "ideas get stolen constantly" sometimes fellow scientists will omit certain details of their research protocols in presentations or publications. Many researchers may go into science primarily with a desire to produce knowledge, but its competitive structure can inculcate desires for recognition and career advancement.

Vivid examples of the competition for credit and status can be found in cases of fraud, although they go well beyond mere bias in science. Consider, for instance, what motivated Dietrich Stapel, the infamous data-fabricating social psychologist. There is no theme in his research that supports a particular moral or political ideology, such as socialism or conservatism. There doesn't even appear to be a particular theory of the human mind that Stapel's work supports. He wasn't known for an overarching framework, such as prospect theory, or even a famous mechanism, such as confirmation bias, moral licensing, or the fundamental attribution error. Stapel also didn't seem to accrue much financial gain from, say, high-profile speaking engagements or a self-help book centered on a key finding, such as "power posing." His own rationalization is that he was on a "quest for aesthetics, for beauty" in the data he reported, but a New York Times interviewer reports that Stapel "didn't deny that his deceit was driven by ambition" (Bhattacharjee 2013) that is, credit or social status. 
Similar stories of course crop up in the natural sciences as well (Stroebe et al. 2012). Across a diverse range of scientific fields, many questionable research practices are largely explicable in terms of the desire for personal gain. Financial gains in science, particularly academia, are often small, but the rewards of social credit are substantial. Indeed, one needn't be motivated by the desire to land a job or a more prestigious appointment. One of the most powerful drives among deeply social creatures like us is to acquire and maintain recognition, status, pride, or respect among peers. If to achieve such social status and approval we will engage in violence (Fiske \& Rai 2014), p-hacking is a breeze. Yet this powerful motive is common among human beings generally, not just social scientists. Concern with competition and social status is a natural feature of human life, grounded in our having evolved to live in groups saturated with social hierarchies and norms (Henrich 2016).

Overall, the framework of motivated reasoning reveals an approximate parity between the natural and social sciences primarily through two mutually reinforcing claims. First, research in the natural sciences is also susceptible to various values, including moral, political, and other ideological motivations that otherwise seem endemic to social science. Second, ideological motives are generally minor compared to other motivations present in both domains, particularly credit but also profit. Of course, in some cases research has been influenced by ideology. Progressive values appear to have influenced psychological studies of conservatism and prejudice (Duarte et al. 2015), and staunch ideological opposition to government regulation has influenced geoscience independently of a desire for profit (Oreskes \& Conway 2010). However, our concern is not with particular instances but general trends, which can serve as grounds for comparing broad scientific domains.

\subsection{Similar Patterns of Bias}

We've seen that the basic motivations throughout science are the same, particularly desires for credit, profit, ideology, and knowledge. Key incentives are also similar (e.g. publish or perish, acquire grant funding), as are the methods (experiments, interviews, meta-analyses, theory building, case studies, etc.). Accordingly, we've seen that questionable research practices arise equally in all scientific domains (Section 2). However, one might argue that there must be different social arrangements or norms that give rise to greater bias in social science, because that domain has particularly low replication rates, high publication bias, and other patterns indicative of motivated reasoning.

Some systematic analyses of scientific literatures do purport to reveal significant differences in such patterns. An analysis of thousands of papers across scientific disciplines suggests that the bias in favor of publishing positive, as opposed to null, results is more common in the social sciences (Fanelli 2010; see also Franco et al. 2014). This is just one of many potential biases in science, and the parity thesis does not insist on symmetry for each. However, a large random sample of meta-analyses in the physical, biological, and social sciences provides a more comprehensive investigation of multiple biases (Fanelli, Costas, \& Ioannidis 2017). The authors found some evidence that the social science literature more strongly exhibits some patterns that lead to an overestimation of effect sizes, such as the tendency to publish larger effects for smaller studies and a decline in the magnitude of particular effects over time as they are replicated.

However, such analyses reveal more commonalities than differences among scientific domains. In their comprehensive examination of meta-analyses, Fanelli and co- 
authors (2017) conclude that across all scientific domains one ought to "interpret with caution results of small, highly cited, and early studies" (5), which tend to overestimate effects due to a range of factors, including industry influence and pressures to publish among early-career researchers. Although some statistically significant differences emerged between the social sciences and the physical sciences (less commonly the biological sciences), there were only a few differences out of the six key bias patterns. Moreover, the authors clarify that the differences are "small in magnitude and not consistently observed across robustness analyses" (4). Indeed, most of the patterns measured across all domains were "relatively small," having only "accounted for $1.2 \%$ or less of the variance in reported effect sizes" of the sampled meta-analyses (5). Dwelling on such minor differences between scientific domains misses the forest for the trees.

Examinations of meta-analyses provide one important aerial view, but we can also zoom in to remind ourselves that many of these patterns of bias are quite visible outside of the social science literature. Publication bias, for example, is on full view in various natural sciences, from biology to epidemiology (Pautasso 2010). One analysis of nearly 600 trials in the database ClinicalTrials.gov found that over a quarter had not been published five years after completion in 2009 , the vast majority of which had no results posted in the database (Jones et al. 2013). Non-publication of results was more common among trials funded by industry, although publicly funded trials can exhibit a bias against reporting null results too (recall Kaplan \& Irvin 2015). Consider also that a recent attempt to replicate 53 published findings in cancer research was only able to reproduce $11 \%$ of the effects (Begley $\&$ Ellis 2012). Although this does not by any means reflect a precise estimate of the replication rate in oncology, other attempts to confirm published findings also report low success rates (e.g. 20-25\% in Prinz et al. 2011). Indeed, replications can be even more difficult when experiments involve a single crucial observation that is difficult to repeat in rare circumstances or with inaccessible populations of people and other organisms. Studies of rare brain disorders, for example, are sometimes published in top journals like Science and shape the field with only a sample of two patients (e.g. Anderson et al. 1999). With small samples and rare circumstances that are difficult to repeat in many natural sciences, findings are more likely to be influenced by biases (Ionnidis 2005).

Of course, one field or literature does not represent the whole of either natural or social science. Financial conflicts of interest are legion in medicine but comparatively infrequent in cultural anthropology. Political bias, in the form of a motivation to promote a preferred ideology, is probably more frequent in political science and economics than in chemistry. Some such comparisons between individual disciplines and individual biases might be fruitful (Fanelli et al. 2017). However, when it comes to the influence of values generally, the various sciences are more alike than they are unalike. The general explanation for why an approximate parity holds between natural and social science is precisely that there is little that could unify a heterogenous group like the natural sciences while distinguishing it from the social sciences in terms of bias. Each shares the same mechanism of motivated reasoning which can operate on a diversity of motives among researchers.

Consider an analogy with dogs. Although there may be interesting differences between individual dog breeds, cleaving all dogs into those with spots and those without will not yield many informative differences, except in terms of spots. Dogs in both groups will generally be susceptible to training or disease, and any differences observed are likely 
to be minor compared to commonalities. Similarly, natural and social science are defined by their subject matters, not their norms or patterns that appear in some literatures. There is little reason to expect a systematic connection between a wide range of topics and the values that can influence their investigation. The ideology motive may seem to be an exception, since moral, political, and social values are frequently the subject of investigation across the social sciences. However, we've seen that moral and political values play only one role, and a relatively minor one compared to others.

\section{Defending the Parity Claim}

The presumptive case in favor of the parity claim might be sufficient if there were no powerful objections to it. Although extant analyses of scientific literatures do not upset parity, there may be general reasons to believe that various values have a significantly greater influence in the social sciences that isn't easily detectable in meta-analyses, replication efforts, and similar literature patterns. We'll now consider general reasons for rejecting parity and see that the rebuttals will continue to highlight our two mutually reinforcing claims of susceptibility and minority.

\subsection{Social Science as Politically Biased?}

Even if tribalism is equally present among both liberals and conservatives (Ditto et al. 2019), ideological influences could be more prevalent in social science if it has significantly less political diversity.

Several studies have mined voter registration data to determine how many Democrats versus Republicans there are among the faculty at elite liberal arts colleges in the United States (e.g. Klein \& Stern 2005). One of the most recent voter registration studies examined data on more than 5,000 professors and across many academic disciplines, but only at rather elite colleges, namely, the top 51 liberal arts colleges ranked in the U.S. News in 2017 (Langbert 2018). The mean Democratic-to-Republican ratio was overall quite high at about 10:1 (rounded to the nearest whole number). Broken down by domain, the mean Democratic-to-Republican ratio among this sample of social scientists was 12:1 while it was 6:1 for those working in sciences regarded as "hard" (e.g. chemistry, physics, and engineering). So, by this measure, there does appear to be more political homogeneity among social scientists employed at elite liberal arts colleges like Oberlin and Bryn Mawr.

Less extreme differences have been found by surveying nearly 1500 professors from a wider range of American universities (Gross \& Simmons 2007). Across the board, slightly more professors in the social sciences identified as liberal (58\% liberal, 37\% moderate, $5 \%$ conservative) compared to those in physics/biological sciences ( $45 \%$ liberal, $47 \%$ moderate, $8 \%$ conservative). Similarly small differences can be found in the 2009 Pew survey of scientists. Like social scientists, the natural scientists surveyed skewed liberal: about half describe themselves as outright liberal and a large majority $(81 \%)$ identify with the Democratic party or lean that way. Remarkably, though, only a narrow margin of the scientists (9\%) described themselves as conservative (compared to $37 \%$ of the general public). 
So social scientists are only slightly more politically homogenous than natural scientists, and there are few conservatives in either group. But presumably few physicists do research that could be shaped by their political views. Perhaps even slightly less ideological diversity could sway more social research because its findings are more often relevant to social policy. One recent study of abstracts in political psychology reports that conservatism is described more negatively and is more likely the target of explanation, compared to liberalism (Eitan et al. 2018). And political ideologies seem to have led some social scientists to even fabricate data whole cloth, as in the case of Michael LaCour who attempted to show that attitudes toward same-sex marriage are more likely to change after talking with a gay canvasser (Konnikova 2015).

However, the extent of the ideology motive can easily be overblown and is fairly consistent across domains of science. The study of political ideology itself is but a small portion of psychological science, so we can't generalize across other areas of study within the social sciences. Moreover, a recent analysis of nearly 200 psychology articles found that their political slant was not strongly related to their replication success, sample size, or effect size (Reinero et al. 2020). Finally, although we tend to think of findings in natural science as disconnected from moral or social issues, many natural sciences have long been politicized, from the persecution of Galileo for heliocentrism to environmental regulations of acid rain and development of the atomic bomb. Connections among political values and natural sciences continue into the $21^{\text {st }}$ century, of course. Geology, biology, biomedicine, neuroscience, and physics, for instance, have direct implications for many hotly debated issues of policy and ideology, including climate change, evolution, mandatory vaccinations, free will (and punishment), sex/gender differences, and intelligent design of the cosmos (see e.g. Solomon 2001; Oreskes \& Conway 2010; Elliott 2017; Peterson 2019). Not only do preachers and politicians have a vested interest in certain empirical findings or conclusions; natural scientists too are people with values and policy preferences, which can influence the questions they ask, the methods used to test hypotheses, and the portrayal of their results.

More importantly, as we've seen, ideological motives are but one of many that can influence research practices and interpretation of data. The desire for credit (status, recognition, prestige) and profit (financial gain) are at least equally present and plausibly more prevalent. So, even if there is less political diversity in social science, and even if that's important to correct (Duarte et al. 2015), it's not enough to demonstrate greater bias within social science, compared to natural science. Consider an analogy. Suppose two cars share the same major defects - faulty seatbelts, say-but one also has a small scratch on the fender. In terms of defects, these two cars are more alike than they are different. Put in terms of strengths instead of flaws, imagine two co-workers, A and B, share nearly all of the same virtues - they're both exceptionally productive and cooperative. But $\mathrm{A}$ is also extremely punctual. It's true in one sense that A is better than B, but the two are more alike than different. We wouldn't expect A to receive higher pay increases than B.

\subsection{Moral Values as Especially Powerful?}

A natural follow-up is that, while the profit and credit motives can be found in both natural and social science, moral motives are more powerful or prevalent in social science. After all, moral values often rise to the level of convictions or sacred values, which can function as such rigid fixpoints that they cloud judgment in particularly powerful ways (Tetlock 
2003). One line of research does suggest that strong moral convictions, compared to strong non-moral attitudes, make people less tolerant of opposing viewpoints and less inclined to work with opponents to resolve disagreements (Skitka et al. 2005).

There are two ways to alleviate this concern. First, moral convictions obviously affect natural science as well. We've already seen how values influence the production and interpretation of climate science and biomedicine (Kahan et al. 2012; Oreskes \& Conway 2010). Similar fervor surrounds research on the genetics of intelligence (Kampourakis 2019) and sex/gender differences at the biological levels of hormones and neurotransmitters (Fine 2010). Again, large portions of natural science have direct implications for deeply held beliefs connected to moral values - e.g. areas of physics (religion), geoscience (climate change), and neurobiology (sex essentialism).

Second, we should be wary anyway of focusing too intently on moral and political values, especially when motives provided by financial gain and social credit can be equally, if not more, powerful and prevalent in science. Moreover, not all moral beliefs are convictions or sacred values, and not all convictions are insensitive to contrary evidence. We have all likely witnessed this in our own lives, but it has also been documented experimentally using rigorous methods and open science. For example, most people will assent to the general utilitarian principle "In the context of life or death situations, always take whatever means necessary to save the most lives." But their credence in this belief lowers when presented with a single counter-example from the ethics literature- the famous Transplant scenario, in which a doctor is able to kill one patient in order to use his organs to save five others (Horne, Powell, \& Hummell 2015). Similar results can be found with even more controversial and deeply held attitudes, such as opposition to vaccines. Researchers have found that, compared to arguments that debunk anti-vaccination myths, opponents of vaccinations weaken their views when presented with factual information about the harms of communicable diseases (Horne, Powell, \& Hummell, \& Holyoak 2015).

\subsection{More Confirmation and Less Controversy in Natural Science?}

Even if the natural sciences are just as susceptible to motives that can influence reasoning, one might argue that there is much more subjectivity and controversy in social science, which makes values more influential. As one commentator put it, "the intellectual subjectivity inherent in the social sciences leaves more room for self-serving interpretation of the data than with hard variables," such as "physical objects" (cf. Estes 2012: 4). Similarly, in their discussion of the replication crisis in social psychology, Earp and Trafimow raise the worry that "human behavior is notoriously complex" and humans are not "relatively simple objects or organisms" such as "billiard balls, or beavers, or planets, or paramecia" (2015: 3; see also Fanelli 2010; Duarte et al. 2015: 2). Hypotheses in the natural sciences, in contrast, are arguably tested against evidence from indisputable observables, which might seem more protected against all forms of motivated reasoning.

However, evidence in many natural sciences share these basic characteristics. At the very least, there is always much dispute at the foundations and cutting edges of science, from grand unifying theories in physics to the effectiveness of medical treatments (see e.g. Ioannidis 2005; Stegenga 2018). Even if data under a certain description are indisputable, the data don't interpret themselves, and they can't support or reject a hypothesis without such interpretation. In physics, neurobiology, medicine, and nutrition, for example, it may 
seem that the core data are indisputable, but each area deals with extremely complex phenomena - as complex and mysterious as human behavior-which generates plentiful disputes about which hypotheses are best supported by the accepted empirical evidence. Ultimately, the relevant evidence in social science is just as observable and can be just as indisputable. In psychology, for example, common data points include donation amounts, reaction times, and boxes ticked on a questionnaire. Even qualitative data are often equally concrete and objective phenomena, such as recorded testimonials and observed cultural practices. The wiggle room is primarily in the operationalization and interpretation of data, including quantitative data in the natural sciences, such as t-cells counted, weight lost, neuronal excitation, and the distances objects have traveled.

Moreover, even if it were true that data and phenomena in the social sciences are more complex and contested, this limits the financial incentives that generate more powerful influences. While some researchers might profit from psychology books on selfhelp or sociology books on racial disparities in society, there are many more and much greater opportunities for wealth and recognition among scientists studying the next breakthrough in pharmaceuticals, nutrition, green energy, or biological materials (Oreskes \& Conway 2010; Stegenga 2018). Gains from the development of gratitude journals or the discovery of a new species of primate pale in comparison to the rewards of breakthroughs in cancer or Alzheimer's research. There is thus a positive relationship between the practical applications commonly found in natural science and some of the most powerful motivations, particularly credit and profit. Thus, even if the concepts and theories in social science are more contested, greater certainties in natural science, whether real or imagined, strengthen other more powerful influences in a domain where conflicts of interest abound.

\subsection{Can We Trust the Social Science Used?}

Finally, taking a step back, let's briefly address a worry about the very social science research we've relied on to identify and analyze values in science. The research on motivated reasoning, for example, comes directly from the sort of social science that some regard with suspicion, for apparently being particularly biased. Even if social science research is no more subject to motivated reasoning than natural science, one might conclude from my argument that the former (and thus the latter) are so problematically biased that we can't trust their results.

It is true, so far as it goes, that I assume that some social science research is reliable and reveals facts about human psychology, including the minds of scientists. But that, I take it, is hardly contested in this debate. At any rate, some research is better than others; some studies should be regarded as preliminary and no philosophical conclusion should be staked on one experiment or a small series of studies conducted by one research group (Machery \& Doris 2017). However, motivated reasoning is a commonsense phenomenon that is well-documented and replicated in diverse literatures by multiple labs and supported by meta-analyses. We wouldn't necessarily need the science to raise the worry, but it certainly bolsters the case. Moreover, some of the empirical support for the parity thesis comes from merely qualitative and descriptive statistics (e.g. rates of responses from participants), not inferential statistics such as p-values which have received much scrutiny in the wake of the replication crisis. 


\section{Conclusion}

We have seen how many of the putative biases that affect science can be explained and illuminated in terms of motivated reasoning, which yields a general understanding of how a researcher's goals and values can influence scientific practice (whether positively or negatively). This general account helps to show that it is unwarranted to assume that such influences are significantly more prominent in the social sciences. The defense of this parity claim relies primarily on two key points. First, the natural sciences are also susceptible to the same values found in social science, particularly given that findings in many fields have social or political implications. Second, the ideological motivations that might seem to arise only in social science are minor compared to others. In particular, one's reasoning is more often motivated by a desire to gain social credit (e.g. recognition among peers) than a desire to promote a moral or political ideology. Although there may be discernible differences in the quality of research across scientific domains, all are influenced by researchers' values, as manifested in their motivations.

We began with the notion that bias in science is a problem, and a particularly pressing one given concerns about replicability and questionable research practices. However, I have not attempted to adjudicate whether the influence of any values in natural or social science is ultimately pernicious. My goal has only been to make the case that we ought to treat like cases alike. When value influences are detrimental, we should regard them as disconcerting in both areas of science; when values are innocuous or even beneficial, we ought to treat them as such in both domains. Whether scientific domains are companions in innocence or in guilt, we should recognize that motivated reasoning influences a wide range of research, which makes vivid how inherent values are to the whole enterprise of science.

\section{Acknowledgements}

Versions of this paper were presented at the Philosophy of Science Association, a Philosophy and Neuroscience Workshop organized by John Bickle and Antonella Tramacere, and the Values in Medicine, Science, \& Technology Conference organized by Matt Brown. In addition to the organizers and audience members at these events, I thank the following for feedback on the manuscript: Marshall Abrams, Rajesh Kana, Kevin McCain, and Alexa Tullett. Work on this article was supported by an Academic Cross-Training Fellowship from the John Templeton Foundation. The opinions expressed in this publication are those of the author and do not necessarily reflect the views of the Foundation. 


\section{References}

Anderson, E. (2004). Uses of Value Judgments in Science. Hypatia, 19(1): 1-24.

Anderson, M., Ronning, E., Vries, R., Martinson, B. (2007). The Perverse Effects of Competition on Scientists' Work and Relationships, Science and Engineering Ethics 13(4): 437-461.

Ariely, D. (2012). The Honest Truth About Dishonesty. Harper Collins.

Batson, C. D. (2016). What's Wrong with Morality? Oxford University Press.

Bhattacharjee, Y. (2013). The Mind of a Con Man. The New York Times Magazine. https://www.nytimes.com/2013/04/28/magazine/diederik-stapels-audacious-academicfraud.html

Blanken, I., van de Ven, N., \& Zeelenberg, M. (2015). A Meta-Analytic Review of Moral Licensing. Personality and Social Psychology Bulletin, 41(4), 540-558.

Blum, B. (2018) .The Lifespan of a Lie: The most famous psychology study of all time was a sham. Why can't we escape the Stanford Prison Experiment? Medium. https://medium.com/s/trustissues/the-lifespan-of-a-lie-d869212b1f62

Boghossian, P. (2012). "What is Inference?" Philosophical Studies 169(1): 1-18.

Bortolotti, L. (2010). Delusions and Other Irrational Beliefs. Oxford University Press.

Bright, L. K. (2017). On Fraud. Philosophical Studies 174(2): 291-310.

Brown, M. J. (2013). Values in Science Beyond Underdetermination and Inductive Risk. Philosophy of Science 80(5): 829-839.

Brown, M. J. (2019). Is Science Really Value Free and Objective? From Objectivity to Scientific Integrity. In K. McCain \& K. Kampourakis (Eds.), What is Scientific Knowledge? An Introduction to Contemporary Epistemology of Science. Routledge, pp. 226-242.

Cushman, F. A. (2020). Rationalization is Rational. Behavioral and Brain Sciences, 43 (e28): 159.

Davidson, D. (1963/2001). "Actions, Reasons, and Causes." Reprinted in his Essays on Actions and Events. Oxford University Press.

Ditto, P. H., Liu, B. S., Clark, C. J., Wojcik, S. P., Chen, E. E., Grady, R. H., et al. (2019). At Least Bias is Bipartisan. Perspectives on Psychological Science, 14(2), 273-291.

Ditto, P. H., Pizarro, D. A., \& Tannenbaum, D. (2009). Motivated Moral Reasoning. In D. M. Bartels, C. W. Bauman, L. J. Skitka, \& D. L. Medin (Eds.), The Psychology of Learning and Motivation (Vol. 50, pp. 307-338).

Duarte, J. L., Crawford, J. T., Stern, C., Haidt, J., Jussim, L., \& Tetlock, P. E. (2015). Political Diversity Will Improve Social Psychological Science. Behavioral and Brain Sciences, $38(\mathrm{e} 130), 1-54$.

Earp, B. D., \& Trafimow, D. (2015). Replication, falsification, and the crisis of confidence in social psychology. Frontiers in Psychology, 6(781), 108-11.

Eitan, O., Viganola, D., Inbar, Y., Dreber, A., Johannesson, M., Pfeiffer, T., et al. (2018). Is research in social psychology politically biased? Systematic empirical tests and a forecasting survey to address the controversy. Journal of Experimental Social Psychology, 79, 188-199.

Elliott, K. C. (2017). A Tapestry of Values: An Introduction to Values in Science. Oxford University Press.

Estes, S. 2012. "The Myth of Self-Correcting Science.” The Atlantic. Accessed November 6, 2015, $<$ http://www.theatlantic.com/health/archive/2012/12/the-myth-of-self-correctingscience $/ 266228 />$.

Fanelli, D. (2010). "Positive" Results Increase Down the Hierarchy of the Sciences. PLoS ONE, 5(4), e10068-10.

Fanelli, D., Costas, R., \& Ioannidis, J. P. A. (2017). Meta-assessment of bias in science. Proceedings of the National Academy of Sciences, 114(14), 3714-3719. 
Fine, C. (2010). Delusions of Gender: How Our Minds, Society, and Neurosexism Create Difference. W. W. Norton.

Firestone, C., \& Scholl, B. J. (2016). Cognition does not affect perception: Evaluating the evidence for "top-down" effects. Behavioral and Brain Sciences, 39(e229), 1-77.

Fiske, A. P., \& Rai, T. S. (2014). Virtuous violence: Hurting and killing to create, sustain, end, and honor social relationships. Cambridge University Press.

Franco, A., Malhotra, N., \& Simonovits, G. (2014). Publication Bias in the Social Sciences: Unlocking the File Drawer. Science, 345(6203), 1502-1505.

Fraser, H., Parker, T., Nakagawa, S., Barnett, A., \& Fidler, F. (2018). Questionable research practices in ecology and evolution. PLOS ONE, 13(7), e 0200303-16.

Gebelhoff, R. (2017). "How biased is science, really?" The Washington Post. https://www.washingtonpost.com/news/in-theory/wp/2017/03/31/how-biased-is-sciencereally/

Gobry, P. (2014). "How Academia's Liberal Bias is Killing Social Science." The Week. https://theweek.com/articles-amp/441474/how-academias-liberal-bias-killing-social-science

Goldin, C., \& Rouse, C. (2000). Orchestrating Impartiality: The Impact of "Blind" Auditions on Female Musicians. The American Economic Review, 90(4), 715-741.

Gross, N., \& Simmons, S. (2007). The social and political views of American professors. Working Paper presented at a Harvard University Symposium on Professors and Their Politics. https://www.researchgate.net/profile/Solon_Simmons/publication/287093322/

Haidt, J. (2001). The Emotional Dog and Its Rational Tail. Psychological Review, 108(4), 814 834.

Head, M. L., Holman, L., Lanfear, R., Kahn, A. T., \& Jennions, M. D. (2015). The Extent and Consequences of P-Hacking in Science. PLoS Biology, 13(3), e1002106-15.

Henrich, J. (2016). The Secret of Our Success. Princeton University Press.

Horne, Z., Powell, D., \& Hummel, J. (2015). A Single Counterexample Leads to Moral Belief Revision. Cognitive Science, 39(8), 1950-1964.

Horne, Z., Powell, D., Hummel, J. E., \& Holyoak, K. J. (2015). Countering antivaccination attitudes. Proceedings of the National Academy of Sciences, 112(33), 10321-10324.

Ioannidis, J. P. A. (2005). Why Most Published Research Findings Are False. PLoS Medicine, 2(8), e124-6.

John, L. K., Loewenstein, G., \& Prelec, D. (2012). Measuring the Prevalence of Questionable Research Practices With Incentives for Truth Telling. Psychological Science, 23(5), 524-532.

Jones, C. W., Handler, L., Crowell, K. E., Keil, L. G., Weaver, M. A., \& Platts-Mills, T. F. (2013). Non-Publication of Large Randomized Clinical Trials: Cross Sectional Analysis. British Medical Journal, 347, f6104.

Kahan, D. M., Peters, E., Wittlin, M., Slovic, P., Ouellette, L. L., Braman, D., \& Mandel, G. (2012). The polarizing impact of science literacy and numeracy on perceived climate change risks. Nature Climate Change, 2(6), 732-735.

Kahneman, D. (2011). Thinking, Fast and Slow. Farrar, Straus and Giroux.

Kampourakis, K. (2019). How Are the Uncertainties in Scientific Knowledge Represented in the Public Sphere? In What Is Scientific Knowledge? K. McCain \& K. Kampourakis (eds.). Routledge, pp.288-305

Kaplan, R. M., \& Irvin, V. L. (2015). Likelihood of null effects of large NHLBI clinical trials has increased over time. PloS One 10(8): e0132382.

Kitcher, Philip (2001) Science, Truth, and Democracy. Oxford: Oxford University Press.

Klein, D. B., \& Stern, C. (2005). Political Diversity in Six Disciplines. Academic Questions, 18(1), 40-52.

Koehler, J. (1993). The Influence of Prior Beliefs on Scientific Judgments of Evidence Quality Organizational Behavior and Human Decision Processes 56(1): 28-55. 
Konnikova, M. (2015). How a Gay-Marriage Study Went Wrong. The New Yorker. https://www.newyorker.com/science/maria-konnikova/how-a-gay-marriage-study-wentwrong

Kunda, Z. (1990). The Case for Motivated Reasoning. Psychological Bulletin, 108(3), 480-498.

Langbert, M. (2018). Homogenous: The Political Affiliations of Elite Liberal Arts College Faculty. Academic Questions, 31(2), 186-197.

Longino, H. (1990). Science as Social Knowledge. Princeton University Press.

Machery, E., \& Doris, J. M. (2017). An Open Letter to Our Students. In B. G. Voyer \& T. Tarantola (Eds.), Moral Psychology: A Multidisciplinary Guide. Springer, pp. 127-47.

Mazar, N., Amir, O., \& Ariely, D. (2008). The dishonesty of honest people: A theory of selfconcept maintenance. Journal of Marketing Research, 45(6), 633-644.

Mazar, N., \& Zhong, C. B. (2010). Do Green Products Make Us Better People? Psychological Science, 21(4), 494-498.

May, J. (2018). Regard for Reason in the Moral Mind. Oxford University Press.

Mercier, H., \& Sperber, D. (2017). The Enigma of Reason. Harvard University Press.

Nosek, B. A., Spies, J. R., \& Motyl, M. (2012). Scientific Utopia II: Restructuring incentives and practices to promote truth over publishability. Perspectives on Psychological Science 7(6): 615-631.

Oreskes, N. \& Conway, E. N. (2010). Merchants of Doubt: How a Handful of Scientists Obscured the Truth on Issues from Tobacco Smoke to Global Warming. Bloomsbury Press.

Pallesen, J. (2019). Orchestrating False Beliefs about Gender Discrimination. Medium. https://medium.com/@jsmp/orchestrating-false-beliefs-about-gender-discriminationa25a48e1d02

Pashler, H., \& Wagenmakers, E. J. (2012). Editors' Introduction to the Special Section on Replicability in Psychological Science. Perspectives on Psychological Science, 7(6), 528-530.

Pautasso, M. (2010). Worsening file-drawer problem in the abstracts of natural, medical and social science databases. Scientometrics 85(1): 193-202.

Peplow, M. (2014). Social Sciences Suffer from Severe Publication Bias. Nature. https://www.nature.com/news/social-sciences-suffer-from-severe-publication-bias-1.15787

Peterson, E. L. (2019). Can Scientific Knowledge Sift the Wheat From the Tares? A Brief History of Bias (and Fears about Bias) in Science. In K. McCain \& K. Kampourakis (Eds.), What is Scientific Knowledge? An Introduction to Contemporary Epistemology of Science. Routledge, pp. 195-211.

Pew Research Center. (2009). Public Praises Science; Scientists Fault Public, Media. https://www.people-press.org/2009/07/09/public-praises-science-scientists-fault-publicmedia/

Prinz, F., Schlange, T., \& Asadullah, K. (2011). Believe it or not: how much can we rely on published data on potential drug targets? Nature Reviews: Drug Discovery, 1-2.

Pritschet, L., Powell, D., \& Horne, Z. (2016). Marginally Significant Effects as Evidence for Hypotheses. Psychological Science, 27(7), 1036-1042.

Reinero, D., Wills, J., Brady, W., Mende-Siedlecki, P., Crawford, J., Bavel, J. (2020). Is the Political Slant of Psychology Research Related to Scientific Replicability? Preprint, https://psyarxiv.com/6k3j5/download.

Shermer, Michael. (2016). Is Social Science Politically Biased? Scientific American. 314 (3):73.

Skitka, L. J., Bauman, C. W., \& Sargis, E. G. (2005). Moral Conviction: Another Contributor to Attitude Strength or Something More? Journal of Personality and Social Psychology, 88(6), 895-917.

Solomon, M. (2001). Social Empricism. MIT Press.

Stanley, M. L., \& De Brigard, F. (2019). Moral Memories and the Belief in the Good Self. Current Directions in Psychological Science, 28(4), 387-391.

Stegenga, J. (2018). Medical Nihilism. Oxford University Press. 
Stroebe, W., Postmes, T., \& Spears, R. (2012). Scientific Misconduct and the Myth of SelfCorrection in Science. Perspectives on Psychological Science, 7(6), 670-688.

Summers, J. S. (2017). Post hoc ergo propter hoc: some benefits of rationalization. Philosophical Explorations, 20(sup1), 21-36.

Tetlock, P. E. (2003). Thinking the Unthinkable: Sacred Values and Taboo Cognitions. Trends in Cognitive Sciences, 7(7), 320-324.

Wilholt, T. (2009). Bias and Values in Scientific Research. Studies in History and Philosophy of Science, 40(1), 92-101.

Zollman, K. (2018). The Credit Economy and the Economic Rationality of Science. The Journal of Philosophy 115(1): 5-33. 